\title{
VOICE THROUGH CHOICE: EXPLORING A CHANNEL THROUGH WHICH GENDER INEQUALITY MANIFESTS IN CONTRACEPTIVE USAGE OPTIONS
}

\author{
Dorcas Oladele Omowole
}

6 December 2018

\begin{abstract}
Using data from the 2008 and 2013 Nigeria Demographic and Health Survey (DHS) and Instrumental Variables (IV) probit strategy, I estimate the effect of a wife's negotiation power on the probability of a wife choosing a "cooperative family planning method" . The target sample chosen from the DHS survey is the sample of all married women of reproductive age (15 - 49 years old $)$ who are of the same age or younger than their husbands. The instruments used was the difference in age and education between husband and wife. IV probit results show that a unit increase in the "index of a wife's negotiation power" generates a 10-percentage point z-score increase in the probability of usage of a cooperative contraceptive $^{2}$ method, downwards from the 11-percentage point z-score increase from the probit results. Further investigation shows heterogeneity across the 6 geopolitical regions of the country. Using the North East region as the base sample, the highest difference between the IV probit and probit estimates was in the North Central (0.007) and North West regions (0.03). This research was constrained by unavailability of data to separate women that exclusively use a cooperative contraceptive from women who exclusively use a non-cooperative family planning method. Hence, making the dependent variable diluted by putting together wives who use both cooperative and non-cooperative methods. Another likely explanation for results from the IV probit analysis is that factors affecting the usage of a "a cooperative contraceptive method" are complex. These factors are influenced by a paradoxical society where there are initiatives to end gender inequality the provision of contraceptive options targeted towards women is being prioritized. Targeting contraceptive options and communications towards women entrenches the
\end{abstract}

\footnotetext{
${ }^{1}$ Cooperative methods are those methods that require buy-in from the husband and wife before usage and pose no or fewer health or one-sided burden on the woman (wife). They include withdrawal method, periodic method, male and female condoms. (Note: All reference to woman in the text, are in reference to the woman as wife)

2 Throughout the paper contraceptives is used synonymously with family planning
} 
expectation that preventing contraception is a role reserved for women. This paper argues that by creating awareness about cooperative methods and making alternate contraceptives targeted towards men, there will be balanced expectation and collaboration to choose methods that are cooperative. Those methods would then be used effectively in preventing unwanted contraception by couples. This is pro-gender equality and generates benefits such as better health and respect for women.

\section{Introduction}

Various family planning options targeted towards women have side effects that range from mild to deadly; from nausea to hormonal imbalance to the risk of blood clots. Considering that the act of sex offers benefits to both parties, placing the burden of family planning on the wife does not maximize the wife's utility but gives a higher utility to the husband (negative externality problem). Kohler and Thornton (2012) found that when men were given Conditional Cash Transfers (CCT) to disincentivize sex so as to not to contract HIV/AIDS in Malawi, the CCT was not associated with a decrease but increase in sexual activity among men. Conversely, the CCT led to a decrease in sexual activity among women.

Intimate Partner Violence (IPV) could be either aggressive or subtle. Less attention is paid to the subtle forms of violence because they sometimes go unnoticed or unreported. According to the WHO (2012), the use of any family planning method against one's will is sexually related coercion and a manifestation of sexual violence against the woman. What happens when the will has been overtaken by society's subtle expectations? Rebekah Gee et al (2009) study reports that partner (male) creating difficulty for subject's (female) use of birth control was positively associated with reports of intimate partner violence. The paper ends with the sad conclusion that passes the buck exclusively to women again:

"Contraception is more difficult to navigate for women experiencing IPV. Providers should consider prescribing contraceptive methods for IPV victims that are not partner dependent." 
In addition, this also raises important questions of agency, "what a person is free to do and achieve in pursuit of whatever goals or values he or she regards as important" (Amartya Sen (1985). Klugman and Hanmer (2016) emphasize that agency in all its forms is critical for women's empowerment. Salaam et al (2006) findings are consistent with arguments that men who have violently abused their partners in the past are more likely to react violently to a request for contraceptive use, especially condom use. Their study reports that contraceptive use among abused women was significantly lower than the non-abused women $(\mathrm{p}<0.01)$. Various studies cited by Salaam et al show associations between intimate partner violence and unintended pregnancy. There may be more links between intimate partner violence and unintended pregnancy than contraceptive usage rates among women and unintended pregnancy.

It is appalling that most studies give recommendations within the context of empowering women to choose independently the methods that have these side effects and present arguments that that those methods are better for the woman because she can take them independently. Whereas, trial versions of contraceptives for men are quickly discarded because they have similar side effects as contraceptives for women. Yet some men are not flexible to women choosing methods with no side effects, preferring that women are manipulated into using all sorts of family planning drugs, injections and insertions through various tactics, banking on society's intended or non-intended role as an accomplice.

This research hopes to achieve a paradigm shift in presenting a new lens through which family planning should be viewed by bringing to the front that the solution to intimate partner violence is not more marketing of family planning medications to women but choosing methods that place less burden on the woman as one of the measures through which intimate partner violence reduction initiatives success should be assessed. Hopefully, this paper would also provide potential pathways to solutions to this market failure problem despite its very systemic and entrenched nature.

The paper proceeds as follows: In Section I, I describe the hypothesis for this study and the mechanisms that supports it. Section II presents probit regression estimates and describes the data used for the analysis 
and some of its limitations. Section III proceeds with the IV probit analysis, describes the instruments used and examines regional heterogeneity in IV probit estimates.

\section{Hypothesis}

I hypothesize that difference in age and education between husband and wife negatively affects the ability of a wife to negotiate the use a method that places less burden on her (referred to going forward as "cooperative contraceptive methods") with the husband and also her ability to discuss and take a stand on issues without facing violent outcomes from the husband. This ability to negotiate then informs the choice of contraceptive methods she ends up using. With higher ability to negotiate, she is more likely to use cooperative contraceptive methods and use them successfully.

\section{FIGURE I - HYPOTHESIZED CAUSAL PATHWAY OF INFLUENCE}

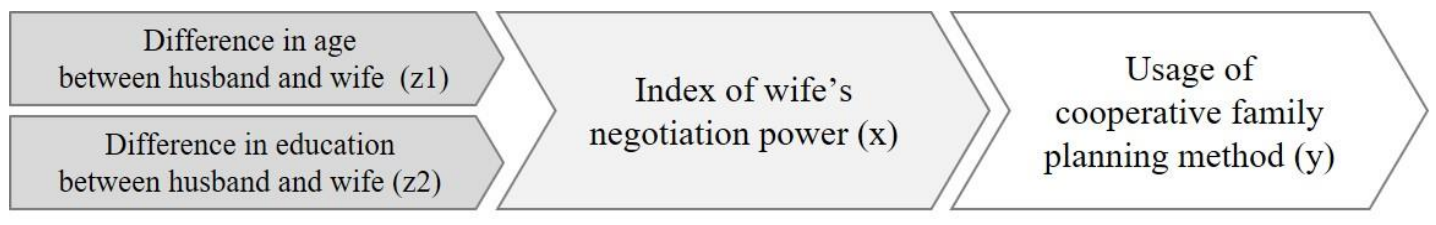

This causal chain works through an underlying mechanism of powerlessness by the wife that is often accentuated when she is younger or less educated than the husband. Also, societal and systemic factors in most African societies even till this day apportion the blame for any "failures" in marriage on the wife. A one-sided responsibility to avoid unwanted contraception is placed on the wife; "a proper woman should know how to take care of herself'. A responsibility she's not able to attain without buy in from her husband and in the absence of this ends up choosing options that are more expensive and negative side effects.

\section{Probit Estimation}

\section{A. Data and Descriptive Statistics}

The data set used for this study was extracted from the Individual Recode (IR) datafiles for the 2008 and 2013 Nigerian Demographic and Health Survey (DHS). The IR data has data for all females interviewed 
who are currently in union. The data set was pooled for two years, 2008 and 2013, so as to have enough samples for the subset for analysis of interest. Data analysis focused on samples where the female interviewed indicated that she is a wife.

The dependent variable was the choice of family planning method currently used by the wife. Family planning methods were aggregated into two categories: cooperative and non-cooperative family planning methods. For this purpose of this research, I define cooperative methods as those methods that require buy-in from the husband and wife before usage and pose no or fewer health or one-sided burden on the woman and non-cooperative methods as those methods that can be used by a woman with the man playing no role in preventing unwanted contraception and often place higher fewer health or one-sided burden on the woman. Family planning methods such as the Lactational Amenorrhea method were dropped from the analysis because it is temporary non-choice-based method during lactation. Cooperative family planning methods was coded as 1 and non-cooperative family planning methods as 0 .

\section{FIGURE I - COOPERATIVE AND NON-COOPERATIVE FAMILY PLANNING METHODS}

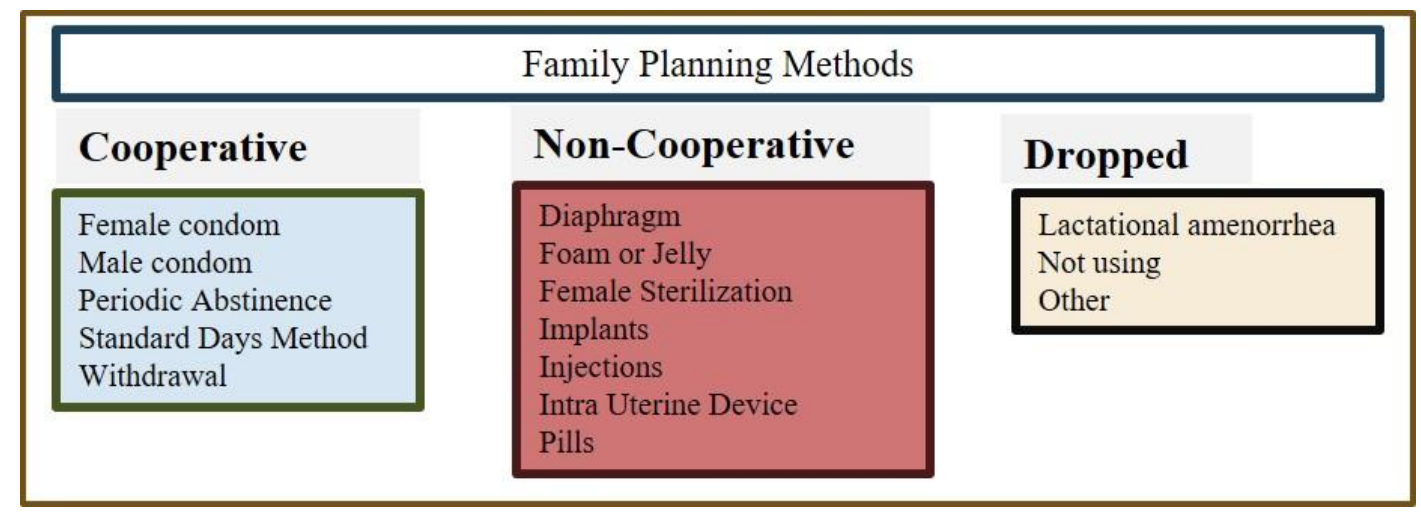

The independent variable, an index of a wife's negotiation power was calculated as the average of the zscore of the following dummy variables - wife can refuse sex (yes =1), wife can ask husband to use a condom (yes = 1), wife beating justified if wife argues with husband (no $=1)$, wife beating justified if wife refuses sex $($ no $=1)$. The two latter variables were coded in the data set as yes $=1$ but were recoded as no $=1$ during analysis so as to convert them into positive measures so they tally with the direction of other variables of the measure of a wife's negotiation power. An index calculated using the z-score was 
favoured over an index that is a summation of variables because the interest was addressing impacts of deviations from the observed average. Also observing the index as z-score rather than cumulative measure provide better interpretative value. Therefore, the average of the z-scores for the earlier mentioned dummy variables was calculated and are presented in Table I. The range of z-scores is widest for the variable "beating justified for refusing sex" and most narrow for the variable "can ask condom". Although the correlation between the two justification for wife beating is 0.6 , neither of the variables was dropped.

TABLE I - DESCRIPTIVE STATISTICS: INDEX OF WIFES' NEGOTIATION POWER VARIABLES

\begin{tabular}{|l|c|c|c|c|c|c|}
\hline & Mean & Std. Dev & Min & Max & Range & Obs \\
\hline Can ask condom (dummy (yes) = 1) & 0.64 & 0.48 & 0 & 1 & & 8,072 \\
\hline Can refuse sex (dummy (yes) =1) & 0.83 & 0.38 & 0 & 1 & & 8,073 \\
\hline Beating justified for arguing (dummy (no) =1) & 0.82 & 0.38 & 0 & 1 & & 8,000 \\
\hline Beating justified for refusing sex (dummy (no) =1) & 0.87 & 0.33 & 0 & 1 & & 7,977 \\
\hline Can ask condom (z-score) & 0 & 1 & -1.32 & 0.75 & 2.07 & 8,072 \\
\hline Can refuse sex (z-score) & 0 & 1 & -2.19 & 0.46 & 2.65 & 8,073 \\
\hline Beating justified for arguing (z-score) & 0 & 1 & -2.16 & 0.46 & 2.62 & 8,000 \\
\hline Beating justified for refusing sex (z-score) & 0 & 1 & -2.61 & 0.38 & 2.99 & 7,977 \\
\hline Index of wife's negotiation power & 0.002 & 0.62 & -2.07 & 0.51 & 2.58 & 7,932 \\
\hline
\end{tabular}

Table II presents descriptive statistics for the main variables of interest. About 47.5 percent of our sample currently use a cooperative family planning method. In the DHS questionnaire for Nigeria, this question is a multiple response question (see APPENDIX I) and the DHS data file does not indicate if the woman currently uses multiple methods because this response was coded in one column. Therefore, response is streamlined to just one method, while there is evidence both from the questionnaire design and anecdotal evidence that a woman may use multiple methods per time, combining both cooperative and noncooperative methods, for example, using pills and condoms, or periodic abstinence and spermicide jellies, for dual contraceptive protection. The analysis would have been more targeted if there was data for women using exclusively cooperative planning methods or a combination of cooperative family planning 
methods only. However, using at least one of the cooperative family planning method shows a tilt in preference to this method and an indicator that a woman is able to discuss sex with the partner in a way that makes the use of this method is possible. Therefore, this provides a good proxy for usage of cooperative methods. Knowledge of ovulation period, being of catholic region and living in rural area were included as the main control variables. The ovulation period is midway between a woman's menstrual period. Within the number of days when a woman is ovulating is when she could get pregnant. Therefore, knowledge of ovulation period is an important consideration and beginning point for a woman interested in using cooperative family planning methods. During these periods, she might either decide to abstain or use a condom. The DHS survey presented five options to the women asking them to indicate which of the time specified was the ovulation period. Asking respondents directly if they knew their ovulation period would generate positive responses higher than the actual from women who may be embarrassed that they do not know saying yes, they do. A dummy variable was generated for this categorical variable with correct response coded as 1 and all other responses coded as 0 . The percentage of women who got this question correctly was 31.7 percent. In Rebekah Gee et al (2009) study in Philadelphia, similar method was used in asking this question and about 50 per cent indicated the right response. The fact that not all women know when they are most fertile is an indication there is inadequate focus on contraceptive methods dependent on this knowledge causing less attention to be paid to it. Also, knowing one's ovulation could be of no consequence if the time of sex is externally and independently determined by the man. If respondent is catholic was also included as a control variable because strict adherents to catholic religion favour most of the options identified as cooperative methods. Not including this as a control would bias our estimate upwards. Rural areas are also more likely to use a cooperative planning method because the methods are free or relatively less costly or because the health facility to obtain some of the non-cooperative family planning methods is inaccessible. 5.4 to 6.6 percent of the sample was from the North East and North West region respectively. This does not signify an under representation for some regions. DHS surveys are randomized and sample per region is based on population of those areas so as to make possible nationwide estimations. Although the DHS also makes 
region specific estimations for survey variables, having larger samples in these regions especially for analysis using a subset of the total sample could help with generating more significant findings for researchers. The difference in age and total years of education between husband and wife was used to instrument for the independent variable. The reason for this choice and proof of validity of instruments would be discussed in section III.

TABLE 2 - DESCRIPTIVE STATISTICS

\begin{tabular}{|l|l|c|c|r|}
\hline Variable Type & Description & Mean & Std. Dev & Obs \\
\hline Dependent & Usage of cooperative family planning method & 0.475 & 0.499 & 8,086 \\
\hline Independent & Index of negotiation power (wife) & 0.002 & 0.619 & 7,932 \\
\hline Control & Knows ovulation period & 0.317 & 0.4654 & 8,082 \\
\hline Control & Catholic religion & 0.149 & 0.357 & 8,059 \\
\hline Control & Rural area & 0.396 & 0.489 & 8,086 \\
\hline & Urban area & 0.604 & 0.489 & 8,086 \\
\hline Control & North Central & 0.205 & 0.403 & 8,086 \\
\hline & North East & 0.054 & 0.226 & 8,086 \\
\hline & North West & 0.066 & 0.250 & 8,086 \\
\hline & South East & 0.156 & 0.362 & 8,086 \\
\hline & South South & 0.177 & 0.382 & 8,086 \\
\hline & South West & 0.341 & 0.474 & 8,086 \\
\hline Instruments & Age difference between husband and wife & 8.70 & 6.27 & 8,086 \\
\hline & Education difference between husband and wife & 0.91 & 4.24 & 8,086 \\
\hline
\end{tabular}

\section{B. Probit Estimates}

Table III reports probit estimates of the relationship between a wife's use of a cooperative family planning method and index of wife's negotiation power. The baseline estimating equation is:

$$
\mathrm{C}_{\mathrm{i}}=\mathrm{P} \beta+\mathrm{X} \beta_{1}+\varepsilon_{\mathrm{i}}
$$

equation (1)

$\underline{C_{i}}$ denotes usage of a cooperative family planning method, $\underline{P}$ denotes index of a wife's negotiation power, $\underline{\beta}$ is the estimated coefficient of the effect of wife's negotiation power on the usage of cooperative family 
planning method, $\underline{\beta}_{1}$ is the vector of unknown parameters, $\underline{X}$ denotes the vector of exogenous variables representing the control variables and $\underline{\varepsilon}_{\mathrm{i}}$ represents the error term in the equation.

The regression without control variables in column I show that a one unit increase in the z-score of index of woman's negotiation power is associated with a 11-percentage point increase in the probability of usage of a cooperative family planning method. Although most probit coefficients are small in magnitude, they are statistically significant. The coefficient for South East region has the largest magnitude; being in the South East is associated with a 48-percentage point increases in the probability that a woman's uses a cooperative family planning method compared to the North East (the base region).

TABLE 3 -PROBIT REGRESSIONS

Dependent variable: Usage of cooperative family planning method

\begin{tabular}{|c|c|c|c|c|c|}
\hline 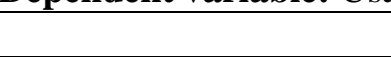 & (1) & $(2)$ & (3) & (4) & (5) \\
\hline Index of negotiation & $\begin{array}{c}0.111 \\
(0.008)^{* * *}\end{array}$ & $\begin{array}{c}0.106 \\
(0.009) * * *\end{array}$ & $\begin{array}{c}0.106 \\
(0.009)^{* * *}\end{array}$ & $\begin{array}{c}0.092 \\
(0.009)^{* * *} \\
\end{array}$ & $\begin{array}{c}0.066 \\
(0.009)^{* * *}\end{array}$ \\
\hline Knows ovulation period & & $\begin{array}{c}0.058 \\
(0.012)^{* * *}\end{array}$ & $\begin{array}{c}0.051 \\
(0.012)^{* * *}\end{array}$ & $\begin{array}{c}0.049 \\
(0.012)^{* * *}\end{array}$ & $\begin{array}{c}0.009 \\
(0.011)\end{array}$ \\
\hline Catholic & & & $\begin{array}{c}0.183 \\
(0.015)^{* * *}\end{array}$ & $\begin{array}{c}0.186 \\
(0.015)^{* * *}\end{array}$ & $\begin{array}{c}0.010 \\
(0.016)^{* * *}\end{array}$ \\
\hline Rural area (a) & & & & $\begin{array}{c}-0.105 \\
(0.011)^{* * *}\end{array}$ & $\begin{array}{c}-0.089 \\
(0.011)^{* * *}\end{array}$ \\
\hline North Central & & & & & $\begin{array}{c}0.119 \\
(0.028)^{* * *}\end{array}$ \\
\hline North West & & & & & $\begin{array}{c}-0.132 \\
(0.034)^{* * *}\end{array}$ \\
\hline South East & & & & & $\begin{array}{c}0.487 \\
(0.029) * * *\end{array}$ \\
\hline South South & & & & & $\begin{array}{c}0.309 \\
(0.0274)^{* * *}\end{array}$ \\
\hline South West & & & & & $\begin{array}{c}0.268 \\
(0.027)^{* * *}\end{array}$ \\
\hline Pseudo R2 & 0.0137 & 0.0158 & 0.0286 & 0.0364 & 0.1121 \\
\hline Wald Chi2 & 148.31 & 171.00 & 304.86 & 385.06 & 1064.00 \\
\hline Obs & 7,932 & 7,928 & 7,901 & 7,901 & 7,901 \\
\hline
\end{tabular}

Note: For all regressions Prob > chi $2=0.0000$ (indicating a strong first stage); Robust standard errors in parentheses (* significant at 10\%; **significant at 5\%; ***significant at $1 \%$ ); urban area is the base sample for area type; North East is the base sample for the regions 


\section{Probit Estimation}

However, index of a woman's negotiation power is not randomly assigned. It is determined also by other unobservable variables in our error term, therefore, omitted variables bias is a concern. For example, the level of sensitization or marketing of specific family planning methods could vary. This means the correlation between the regressors and the error term is not zero $(E(X, u) \neq 0)$, and the results of the probit estimation are inconsistent. I am also concerned about reverse causality; a woman's usage of a cooperative family planning method could be as a result of her ability to negotiate or it could be that her ability to negotiate makes it possible for her to use a cooperative family planning method. Measurement error could also be a concern because I do not have data for wifes that exclusively use cooperative family planning methods. Existing data is a good proxy because this is applicable to all the samples surveyed.

A. Difference in age and education between husband and wife I instrument for index of a wife's negotiation power using two instruments; difference in age and difference in total years of education between husband and wife. These instruments satisfy both the conditional independence and exclusion restriction assumptions. They are not related to other factors in our error term $(\operatorname{cov}(\mathrm{z}, \mathrm{u})=0)$. Any couple irrespective of age or education difference can choose or use either methods of family planning. The instruments impacts method used, only through their influence on a wife's negotiation power. The Wald test of exogeneity has a Prob $>$ chi $2=0.0000$ for all IV probit regressions (see TABLE 5) showing that our instruments are relevant $(\operatorname{cov}(\mathrm{x}, \mathrm{z}) \neq 0)$.

TABLE 4 - DESCRIPTIVE STATISTICS FOR INSTRUMENTS

\begin{tabular}{|l|l|c|c|c|c|c|}
\hline & & Mean & $\begin{array}{l}\text { Std. } \\
\text { Dev }\end{array}$ & Min & Max & Obs \\
\hline Instrument1 & Age differential between husband and wife & 8.70 & 6.27 & $0^{+}$ & 55 & 8,086 \\
\hline & Husband's age & 43.00 & 9.78 & 20 & 95 & 8,086 \\
\hline & Wife's age & 34.31 & 7.33 & 16 & 49 & 8,086 \\
\hline Instrument2 & Husband minus wife's years of education & 0.91 & 4.24 & -15 & 19 & 8,086 \\
\hline & Husband's years of education & 10.33 & 4.70 & 0 & 21 & 8,086 \\
\hline & Wife's years of education & 9.42 & 4.59 & 0 & 20 & 8,086 \\
\hline
\end{tabular}

${ }^{+}$samples where wife indicates that she's older than the husband was dropped because this is not the norm 


\section{B. IV Probit estimates}

Equation (1) describes the relationship between usage of cooperative method of family planning and index of a wife's negotiation power. In addition, I estimate the effect of the instruments on the independent variable:

$\mathrm{I}_{\mathrm{i}}=\alpha_{1} \mathrm{Z}_{1}+\alpha_{2} \mathrm{Z}_{2}+\mu_{\mathrm{i}}$

equation (2)

$\underline{I}_{\underline{i}}$ denotes index of a wife's negotiation power, $\underline{z}_{1}$ denotes the difference in age between husband and wife,

$\alpha_{1}$ is the estimated coefficient of $\mathrm{z}_{1}$ on $\mathrm{I}_{1}, \mathrm{z}_{2}$ denotes the difference in education between husband and wife, $\underline{\alpha}_{2}$ is the estimated coefficient of $\mathrm{z}_{2}$ on $\mathrm{I}_{\mathrm{i}}$, and $\underline{\mu_{\mathrm{i}}}$ represents the error term.

However, for all IV probit regression coefficients, the estimates are slightly lower than the probit estimates.

TABLE 5 -IVPROBIT REGRESSIONS: MARGINAL EFFECTS

Dependent variable: Usage of cooperative family planning method

\begin{tabular}{|c|c|c|c|c|c|}
\hline & (1) & (2) & (3) & (4) & (5) \\
\hline Index of negotiation & $\begin{array}{c}0.100 \\
(0.034) * * *\end{array}$ & $\begin{array}{c}0.0960 \\
(0.0359) * * *\end{array}$ & $\begin{array}{c}0.0960 \\
(0.0362)^{* * *}\end{array}$ & $\begin{array}{c}0.0836 \\
(0.0407)^{* *}\end{array}$ & $\begin{array}{l}0.06242 \\
(0.0616)\end{array}$ \\
\hline Knows ovulation period & & $\begin{array}{c}0.0506 \\
(0.0168)^{* * *}\end{array}$ & $\begin{array}{c}0.0442 \\
(0.0162)^{* * *}\end{array}$ & $\begin{array}{c}0.0431 \\
(0.0167)^{* * *}\end{array}$ & $\begin{array}{l}0.00609 \\
(0.0166)\end{array}$ \\
\hline Catholic & & & $\begin{array}{c}0.180 \\
(0.0224) * * *\end{array}$ & $\begin{array}{c}0.184 \\
(0.0246) * * *\end{array}$ & $\begin{array}{c}0.0995 \\
(0.0227)^{* * *}\end{array}$ \\
\hline Rural area (a) & & & & $\begin{array}{c}-0.0967 \\
(0.0230) * * *\end{array}$ & $\begin{array}{c}-0.08502 \\
(0.0253) * * *\end{array}$ \\
\hline North Central & & & & & $\begin{array}{c}0.113 \\
(0.045)^{* *}\end{array}$ \\
\hline North West & & & & & $\begin{array}{c}-0.133 \\
(0.0358) * * * \\
\end{array}$ \\
\hline South East & & & & & $\begin{array}{c}0.4805 \\
(0.0929)^{* * *}\end{array}$ \\
\hline South South & & & & & $\begin{array}{c}0.296 \\
(0.0768) * * *\end{array}$ \\
\hline South West & & & & & $\begin{array}{c}0.254 \\
(0.076)^{* * *}\end{array}$ \\
\hline Obs & 7,932 & 7,928 & 7,901 & 7,901 & 7,901 \\
\hline Wald chi2 & 637.09 & 793.17 & 1314.23 & 1798.12 & 4224.12 \\
\hline Wald test of exogeneity (chi2) & 95.51 & 88.31 & 84.86 & 72.29 & 31.40 \\
\hline Difference in age & $\begin{array}{c}-0.0059 \\
(0.0008) * * *\end{array}$ & $\begin{array}{c}-0.0059 \\
(0.0008)^{* * *}\end{array}$ & $\begin{array}{c}-0.0060 \\
(0.00077)^{* * *}\end{array}$ & $\begin{array}{c}-0.0056 \\
(0.0008) * * *\end{array}$ & $\begin{array}{c}-0.00467 \\
(0.00073)^{* * *}\end{array}$ \\
\hline Difference in education & $\begin{array}{c}-0.0106 \\
(0.00113)^{* * *}\end{array}$ & $\begin{array}{c}-0.0101 \\
(0.00115)^{* * *}\end{array}$ & $\begin{array}{c}-0.009 \\
(0.00108)^{* * *}\end{array}$ & $\begin{array}{c}-0.0086 \\
(0.00113)^{* * *}\end{array}$ & $\begin{array}{c}-0.0031 \\
(0.00105)^{* * *}\end{array}$ \\
\hline
\end{tabular}


Note: For all regressions wald test of exogeneity (chi2) has Prob > chi2 $=0.0000$ (indicating a strong first stage); Robust standard errors in parentheses (* significant at 10\%; **significant at 5\%; ***significant at 1\%); urban area is the base sample for area type; North East is the base sample for the regions.

\section{Heterogeneity in IV probit estimates}

It is possible that differences between region balance each other out resulting in similar probit and IV probit estimates. To test this assumption, I estimate the relationship between our main variables in the

$\begin{array}{lll}\text { regions using: } \quad \mathrm{C}_{\mathrm{j}}=\mathrm{P}_{\mathrm{j}} \beta_{\mathrm{j}}+\varepsilon_{\mathrm{i}} & \text { equation (4) }\end{array}$

$\underline{C}_{\mathrm{j}}$ denotes usage of a cooperative family planning method in region, $\mathrm{P}_{\mathrm{j}}$ denotes index of a wife's

negotiation power in the region, $\beta_{\mathrm{i}}$ is the estimated coefficient of the effect of wife's negotiation power on the usage of cooperative family planning method in the region, and $\underline{\varepsilon}_{\mathrm{i}}$ represents the error term in the equation.

Compared to coefficients in column (1) of TABLE 5 (the IV probit estimates table), where index of wife's negotiation for the whole sample is $0.100(0.034)^{* * *}$. Table 6 serves two purposes to compare probit and ivprobit analysis between regions and to also compare IV probit coefficient of the main regression for the total sample with that of the regions. Table 7 shows that only the North Central and South East regions has coefficients only marginally higher than the probit $((0.100)$ or IV probit estimates (0.111). However, our instrument is weak in four out of the six regions (indicated in red - TABLE 7) and coefficients are only statistically significant in the North East.

TABLE 6 - PROBIT ESTIMATES REGIONS: MARGINAL EFFECTS

\begin{tabular}{|l|l|c|c|c|c|c|}
\hline & & Coefficient & Pseudo R2 & Wald chi2 & Prob > chi2 & Obs \\
\hline$(11)$ & North East & $0.016(0.023)$ & 0.0013 & 0.51 & 0.4743 & 428 \\
\hline$(12)$ & North Central & $0.119(0.018)^{* * *}$ & 0.0222 & 42.48 & 0.0000 & 1,634 \\
\hline$(13)$ & North West & $0.027(0.021)$ & 0.0043 & 1.72 & 0.1899 & 529 \\
\hline$(14)$ & South East & $0.115(0.019)^{* * *}$ & 0.0245 & 33.13 & 0.0000 & 1,236 \\
\hline$(15)$ & South South & $0.076(0.023)$ & 0.0058 & 10.76 & 0.0010 & 1,379 \\
\hline$(16)$ & South West & $0.04(0.019)$ & 0.0012 & 4.48 & 0.0344 & 2,726 \\
\hline
\end{tabular}


TABLE 7 - IV PROBIT ESTIMATES REGIONS: MARGINAL EFFECTS

\begin{tabular}{|c|c|c|c|c|c|c|c|c|}
\hline & & Coefficient & First st & & & & & Ohs $>$ \\
\hline & & Coemintient & Difference in age & Diff in educ & Wald chi2 & $\operatorname{ch} 12$ & Prob > ch12 & Uos \\
\hline (17) & $\begin{array}{l}\text { North } \\
\text { East }\end{array}$ & $\begin{array}{l}0.015 \\
(0.292) * *\end{array}$ & $\begin{array}{l}-0.006 \\
(0.007)\end{array}$ & $\begin{array}{l}-.0131 \\
(0.012)\end{array}$ & 850.01 & 0.51 & 0.4763 & 428 \\
\hline (18) & $\begin{array}{l}\text { North } \\
\text { Central }\end{array}$ & $\begin{array}{l}0.112 \\
(0.076)\end{array}$ & $\begin{array}{l}-0.003 \\
(0.001) * * *\end{array}$ & $\begin{array}{l}-0.008 \\
(0.002) * * *\end{array}$ & 81.49 & 12.36 & 0.0004 & 1,634 \\
\hline (19) & $\begin{array}{l}\text { North } \\
\text { West }\end{array}$ & $\begin{array}{l}0.024 \\
(0.123)\end{array}$ & $\begin{array}{l}-0.003 \\
(0.0015) * *\end{array}$ & $\begin{array}{l}-0.0003 \\
(0.0014)\end{array}$ & 5.3 & 1.88 & 0.1702 & 529 \\
\hline (20) & $\begin{array}{l}\text { South } \\
\text { East }\end{array}$ & $\begin{array}{l}0.115 \\
(0.105)\end{array}$ & $\begin{array}{l}-0.001 \\
(0.004) * *\end{array}$ & $\begin{array}{l}-0.004 \\
(0.001)\end{array}$ & 279.66 & 0.38 & 0.5390 & 1,236 \\
\hline (21) & $\begin{array}{l}\text { South } \\
\text { South }\end{array}$ & $\begin{array}{l}0.074 \\
(0.228) \\
\end{array}$ & $\begin{array}{l}-0.006 \\
(0.004) \\
\end{array}$ & $\begin{array}{l}-0.0002 \\
(0.001) \\
\end{array}$ & 54.11 & 1.81 & 0.1787 & 1,379 \\
\hline (22) & $\begin{array}{l}\text { South } \\
\text { West }\end{array}$ & $\begin{array}{l}0.03 \\
(0.106)\end{array}$ & $\begin{array}{l}-0.008 * * * \\
(0.002)\end{array}$ & $\begin{array}{l}-0.004 * \\
(0.002) \\
\end{array}$ & 84.57 & 21.57 & 0.0000 & 2,726 \\
\hline
\end{tabular}

Perhaps there are so many unobservable and exogenous factors that inform the choice of usage of cooperative family planning methods versus non-cooperative family planning methods, that makes this choice as good as random and makes the IV identification strategy of less value because there are no observable variables that are truly exogenous. For example, irrespective of difference in age or education, some men might just be more considerate and disciplined than some men due to some in-utero shocks or factors in upbringing. Or perhaps, the culture of masculinity as being fertile and the number of children a man has being a sign of virility make the husband not want to choose a cooperative method because it counters this desire to show off his virility and even when wife chooses to use a non-cooperative method, she does this surreptitiously.

Attempts was also made to explore further heterogeneity focusing on difference in age and years of education. Among these two groups, there was an even split between the use of cooperative versus noncooperative methods -59.7 percent among same age husband and wife and 48.7 percent among husband and wife with the same number of years of education. Probit and IV probit estimates of husband and wife of same age also show lower IV probit estimates. Same for Probit and IV probit estimates of husband and wife with equal number of years of education (APPENDIX IV). Being above or below median age not explored because this is an individual (unit) level choice and a group (survey) average not likely to offer much insight. 


\section{Conclusion}

In the literature, most non-cooperative family planning methods are described as "modern methods," while most cooperative family planning methods are defined as "traditional methods." In a world and especially in developing countries where modernization is a catchy proposition, it would not be strange to find a husband imposing a modern method on the wife in the spirit of modernization just so as to avoid cooperative methods. This power relations merely mirror the values and inequalities of society. Even the DHS survey categorizes family planning methods along this divide. As reiterated throughout this paper, the focus on non-cooperative family planning methods shows how systemic and entrenched into the fabric of society the expectation of the woman as the "contraceptive consumer". Even pharmaceuticals prioritize research into family planning for women because they choose to be convinced that men would not purchase family planning medications. This situation begs the question, "where is the much-heralded global international development commitment to gender equality and female empowerment?" Shouldn't we be taking this commitment a step ahead by incentivizing the production and marketing of family planning methods exclusively for men, emphasizing all family planning methods, especially cooperative family planning methods. So that men and women who do not want to use contraceptives exclusively targeted towards them, can perhaps, find a compromise and work towards making cooperative family planning methods be a win-win for them.

\section{References}

Kohler H and Thornton R. Conditional Cash Transfers and HIV/AIDS Prevention: Unconditionally Promising? World Bank Econ Rev. 2012 Jun 1; 26(2): 165-190.

Lucia Hanmer \& Jeni Klugman (2016) Exploring Women's Agency and Empowerment in Developing Countries: Where do we stand? Feminist Economics, 22:1, 237-

263, doi: 10.1080/13545701.2015.1091087

Rebekah Gee et al. Power over parity: intimate partner violence and issues of fertility control. Am J Obstetrics Gynecology 2009;201:148.e1-7

Salam, M.A., Alim, M.A. \& Noguchi, T. Spousal Abuse Against Women and Its Consequences on Reproductive Health: A Study in the Urban Slums in Bangladesh. Maternal and Child Health Journal (2006) 10: 83. https://doi.org/10.1007/s10995-005-0030-6 
WHO, 2012. Intimate Partner Violence.

http://apps.who.int/iris/bitstream/10665/77432/1/WHO_RHR_12.36_eng.pdf

\section{APPENDIX I}

\begin{tabular}{|c|c|c|c|}
\hline No. & QUESTIONS AND FILTERS & CODING CATEGORIES & SKIP \\
\hline 304 & $\begin{array}{l}\text { Which method are you using? } \\
\text { CIRCLE ALL MENTIONED. } \\
\text { IF MORE THAN ONE METHOD MENTIONED, FOLLOW SKIP } \\
\text { INSTRUCTION FOR HIGHEST METHOD IN LIST. }\end{array}$ & 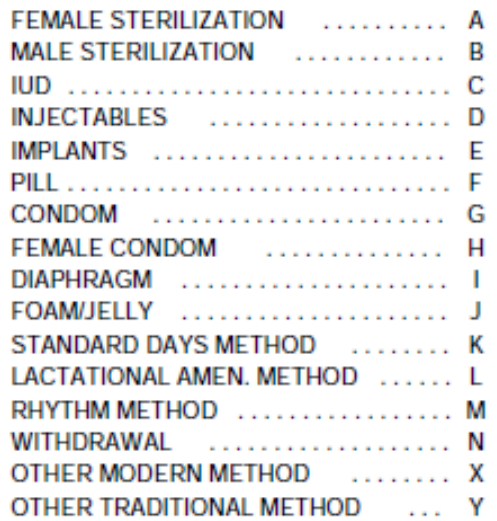 & $\begin{aligned} \longrightarrow & 307 \\
\longrightarrow & 308 \mathrm{~A} \\
\longrightarrow & 308 \mathrm{~A} \\
\longrightarrow & 305 \\
\longrightarrow & 306 \\
\rightarrow & 306\end{aligned}$ \\
\hline
\end{tabular}

\section{APPENDIX II}

\begin{tabular}{|c|c|c|c|c|c|c|c|c|}
\hline \multirow[t]{2}{*}{ Description } & \multicolumn{3}{|c|}{$\begin{array}{l}\text { Usage of cooperative family } \\
\text { planning method }\end{array}$} & \multicolumn{5}{|c|}{ Index of negotiation power (wife) } \\
\hline & Mean & Std. Dev & Obs & Mean & Std. Dev & Min & Max & Obs \\
\hline North Central & 0.331 & 0.471 & 1,634 & 0.104 & 0.677 & -2.07 & 0.514 & 1,634 \\
\hline North East & 83 & 0.387 & 438 & -0.4364 & 0.820 & -2.07 & 0.514 & 428 \\
\hline North West & 0.125 & 0.331 & 541 & -0.132 & 0.711 & -2.07 & 0.514 & 529 \\
\hline South East & 0.759 & 0.428 & 1,258 & -0.005 & 0.576 & -2.07 & 0.514 & 1,236 \\
\hline South West & 0.522 & 0.500 & 2,760 & 0.154 & 0.503 & -2.07 & 0.514 & 2,726 \\
\hline South South & 0.526 & 0.500 & 1,435 & 0.0160 & 0.586 & -2.07 & 0.514 & 1,379 \\
\hline
\end{tabular}

\section{APPENDIX III}

\begin{tabular}{|l|c|c|c|c|r|r|r|r|r|r|}
\hline \multirow{2}{*}{ Region } & \multicolumn{9}{|c|}{ Age difference btwn husband and wife } & \multicolumn{5}{|c|}{ Education difference btwn husband and wife } \\
\cline { 2 - 12 } & Mean & Std. Dev & Min & Max & \multicolumn{1}{l|}{ Obs } & Mean & Std.Dev & \multicolumn{1}{l|}{ Min } & \multicolumn{1}{l|}{ Max } & \multicolumn{1}{l|}{ Obs } \\
\hline $\begin{array}{l}\text { North } \\
\text { Central }\end{array}$ & 8.7 & 6.4 & 0 & 45 & 1,654 & 2.1 & 4.6 & -15 & 18 & 1,654 \\
\hline North East & 10.1 & 6.4 & 0 & 48 & 438 & 2.5 & 4.7 & -12 & 17 & 438 \\
\hline North West & 10.1 & 6.3 & 0 & 35 & 541 & 2.3 & 4.6 & -12 & 19 & 541 \\
\hline South East & 10.4 & 6.6 & 0 & 45 & 1,258 & -1.0 & 4.0 & -15 & 12 & 1,258 \\
\hline South West & 7.6 & 6.0 & 0 & 55 & 2,760 & 0.58 & 3.75 & -12 & 14 & 2,760 \\
\hline South South & 8.33 & 5.68 & 0 & 35 & 1,435 & 0.91 & 3.82 & -15 & 16 & 1,435 \\
\hline
\end{tabular}




\section{APPENDIX IV}

PROBIT ESTIMATES WHEN HUSBAND AND WIFE OF SAME AGE OR EDUCATION

\begin{tabular}{|l|l|c|c|c|c|c|}
\hline & & Coefficient & Pseudo R2 & Wald chi2 & Prob > chi2 & Obs \\
\hline$(1)$ & Agediff $=0$ & $0.175(0.079)^{* *}$ & 0.0255 & 4.42 & 0.0355 & 142 \\
\hline$(2)$ & Educdiff=0 & $0.1032(.0149)^{* * *}$ & 0.0117 & 45.58 & 0.000 & 2,756 \\
\hline
\end{tabular}

IV PROBIT ESTIMATES WHEN HUSBAND AND WIFE OF SAME AGE OR EDUCATION

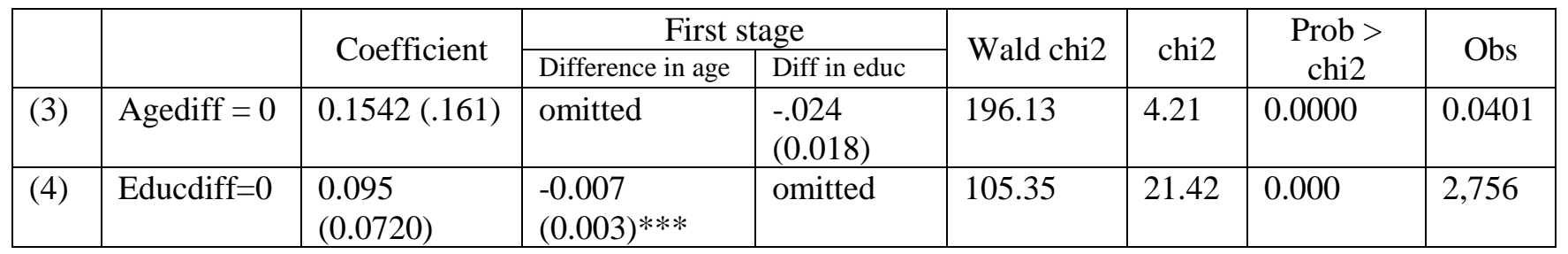

